\title{
A golden age of discovery ${ }^{\dagger}$
}

\author{
David Kingdon
}

\begin{abstract}
summary
Original ideas are needed in developing new interventions for psychosis, and computer-assisted therapy for auditory hallucinations is one such novel approach. As with any early-phase development, it will require further refinement and evaluation. There are now a range of ongoing studies into different intervention strategies and these promise to enhance the therapeutic potency
\end{abstract}

of clinical psychiatrists and mental health teams. If the relative lack of research funding, focus and support from academic sources on this area were to change, even more could be delivered.

\section{Declaration of interest}

D.K. applies for grants to develop psychosocial interventions.
David Kingdon is Professor of Mental Health Care Delivery at the University of Southampton and Honorary Consultant Psychiatrist to Southern Health NHS Foundation Trust.

Mental health research desperately needs new solutions to old problems. Leff and colleagues describe in the Journal a novel approach to coping with distressing voices, which opens up the field to the use of new technologies. ${ }^{1}$ There has been some work on the use of virtual reality in exploring paranoia ${ }^{2}$ but this seems to be the first use as a therapeutic intervention in psychosis. Computerised cognitive-behavioural therapy (CBT) has a longer history in other areas ${ }^{3}$ and this is now extending to the use of smartphone applications.

\section{Contrasting approaches to psychosis}

The findings are preliminary and need further testing but such original approaches suggest that there may be a highway opening up past the cul-de-sac of neurobiological approaches, still promising but not delivering more than 5 years after we last debated their lack of clinical impact. ${ }^{4}$ Neurobiological understanding may help in explaining psychological phenomena, for example, the finding that Broca's area is active when people hallucinate can assist in reattributing voices appropriately to 'inner speech. ${ }^{5}$ Similarly, discussing the fact that antipsychotics affect pathways involved in mediating responses to stress can be helpful to patients in understanding why they might be worth taking. But the empirically derived development of new biological treatments seems to have eluded researchers.

The Rand Corporation, commissioned by major UK, US and Canadian funders, provided a very interesting commentary on this recently. ${ }^{6}$ They attempted to use the retrosight methodologies used in other areas of medicine in mental health, and specifically schizophrenia. This involved identifying a short-list of 'hot' research papers for consideration in case study selection from the late 1980s which at the time appeared to be the most promising for future therapeutic interventions. The Rand Corporation identified two case studies - the discoveries of the $5-\mathrm{HT}_{3}$ receptor $^{7}$ and of cellular growth factor. ${ }^{8,9}$ They followed further work on both and neither have, unfortunately, had an effect on clinical practice. They therefore had to take a different approach and used a 'backward-tracing' approach to selecting case studies. This involved a Delphi consultation asking 'What are the

†See pp. 428-433, this issue most important interventions that have been introduced into practice for the treatment of schizophrenia in the past 5-10 years and yielded significant benefits to patients?' Apart from antipsychotic medication, CBT and early intervention were the most commonly selected advances. Case studies of both are described. In contrast, these developed from original ideas published in very low-impact journals and which were based on unfunded studies. Novel approaches in psychosocial interventions such as that described by Leff and colleagues will initially ask questions rather than provide definitive answers, but these need to be published where they can have most influence on the future of psychiatric research.

\section{Resources for research}

Funding for mental health research remains startlingly low compared with the morbidity that mental disorders cause and this was highlighted recently by the distortion of data presentation in the UK Clinical Research Collaboration Research Analysis ${ }^{9}$ which grouped neurological and mental disorders together. Disaggregating these, again, ${ }^{10}$ demonstrated the continuing relative lack of investment. ${ }^{11}$ The case is therefore being made for more resources but there is also an argument about where these resources are best targeted. There remains a strong bias in high-impact academic journals, universities and some funding organisations towards neurobiological sciences and this has the effect of distorting resource allocation and the ability to fund the 'brightest minds' to more potentially productive pursuits. The 'Catch 22' exists whereby low funding leads to fewer researchers in an area to cite work, which leads to high-impact journals not publishing the work, which in turn leads to lower funding.

Despite these funding and publishing issues, psychological interventions may just be entering a golden age of discovery in the UK. Interest and research into psychological phenomena is increasing rapidly, with the numbers of psychological graduates leaving university growing year on year and the demand for clinical psychology places very high. The links between university departments of clinical psychology and psychiatry can be very productive, especially when the day-to-day clinical practice of psychiatrists meets the more structured therapeutic styles of clinical psychologists and seeks jointly to find solutions to the complex problems that psychosis presents. However, there remains continuing potential for such relationships to develop further, although the reducing numbers of academic psychiatrists and focus of medical schools on further developing biological research does not help this to happen. 


\section{Emerging psychosocial interventions}

The effectiveness of CBT in psychosis compared with treatment as usual has been well demonstrated and led to inclusion in National Institute for Health and Care Excellence and many other international guidelines. Doubts about the distinctive contribution of CBT over supportive therapies, however, remain: a recent Cochrane review ${ }^{12}$ found no difference; as did Lynch and colleagues. ${ }^{13}$ Meta-analyses in this area are fraught with difficulties as, unlike medication, the product 'cognitive therapy for psychosis' varies across studies, as do length of study, outcome measures and, most importantly, study sample. ${ }^{14}$ Replication of studies is necessary but rarely a priority for funding. In the 1990s, the Medical Research Council (MRC)-funded SOCRATES study into early schizophrenia ${ }^{15}$ produced only marginal differences between CBT and treatment as usual, and non-significant differences with supportive therapy. However, when therapy was being offered, clear gains for CBT were accruing - and then the main programme of therapy stopped at 5 weeks; in retrospect, much too early. The MRC-funded MIDAS study of CBT for dual diagnosis recruited patients extremely well but was not successful. ${ }^{16} \mathrm{~A}$ factor may have been that unlike its successful pilot ${ }^{17}$ it did not offer family work, for logistical reasons. Such studies need to be repeated, learning the lessons from their predecessors, as would be occurring with newly developed pharmaceutical products.

The focus of psychosocial intervention studies is narrowing from broad categories such as psychosis and schizophrenia, to symptom-determined areas - paranoia, voices or negative symptoms - or phase-determined interventions, for example, first episode, patients not accepting medication or where clozapine resistance is present. Interventions under investigation or due to be published $^{18}$ include mindfulness for distressing voices, tackling worry in paranoia, behavioural activation, prevention of long-term social disability among young people with emerging psychological difficulties, and effectiveness and cost-effectiveness of body psychotherapy in the treatment of negative symptoms of schizophrenia. Studies developing effective patient-clinician communication in community mental health, reducing negative beliefs about the self in people with persecutory delusions, working with post-traumatic stress disorder and cognitive-behavioural suicide prevention for psychosis are proceeding. Clinical and cost-effectiveness of a contingency management intervention for reduction of cannabis use and of relapse in early psychosis may be promising adaptations of successful interventions used elsewhere. Supported self-management packages for relatives of people with recent-onset psychosis and recovery-focused self-help therapy are also being assessed.

Psychosocial interventions feature prominently in clinical guidelines and are valued by service users. However, there remain major issues around implementation which are being considered by the Improving Access to Psychological Therapies - Severe Mental Illness (IAPT-SMI) programme. ${ }^{19}$ Competency frameworks ${ }^{20}$ are being developed to assist training, and demonstration sites in two National Health Service trusts have been established to spread good practice. Research into these areas has been highly productive and cost-effective; it promises to deliver more in the near future and with the right support and funding can continue to transform our approaches to psychosis. 'We can talk' ${ }^{21}$ and find better ways to do it.
David Kingdon, MD, FRCPsych, University of Southampton, Academic Centre, College Keep, 4-12 Terminus Terrace, Southampton S014 3DT, UK. Email: dgk@soton.ac.uk

First received 18 Jan 2013, accepted 24 Apr 2013

\section{References}

1 Leff J, Williams G, Huckvale MA, Arbuthnot M, Leff AP. Computer-assisted therapy for medication-resistant auditory hallucinations: proof-of-concept study. Br J Psychiatry 2013; 202: 428-33.

2 Freeman D, Pugh K, Vorontsova N, Antley A, Slater M. Testing the continuum of delusional beliefs: an experimental study using virtual reality. J Abnorm Psychol 2010; 119: 83-92.

3 NHS South Central. Computerised Therapy. NHS South Central, 2013.

4 Kingdon D, Young AH. Research into putative biological mechanisms of mental disorders has been of no value to clinical psychiatry. Br J Psychiatry 2007; 191: 285-90.

5 Cleghorn JM, Franco S, Szechtman B, Kaplan RD, Szechtman H, Brown GM, et al. Toward a brain map of auditory hallucinations. Am J Psychiatry 1992; 149: 1062-9.

6 Wooding S, Keyser DJ, Ni Chonaill S, Schultz D, Pincus HA, Pollitt A, et al. Mental Health Retrosight: Final Report on Phase I. RAND Corporation, 2012.

7 Kilpatrick GJ, Jones BJ, Tyers MB. Identification and distribution of 5-HT3 receptors in rat brain using radioligand binding. Nature 1987; 330: 746-8.

8 Richardson WD, Pringle N, Mosley MJ, Westermark B, Dubois-Dalcq M. A role for platelet-derived growth factor in normal gliogenesis in the central nervous system. Cell 1988; 53: 309-19.

9 UK Clinical Research Collaboration. UK Health Research Analysis 2009/10. UK Clinical Research Collaboration, 2012.

10 Kingdon D. Health research funding: mental health research continues to be underfunded. BMJ 2006; 332: 1510

11 Kingdon $D$, Wykes $T$. Increased funding needed for mental health research. BMJ 2013 Jan 22; 346: f402. doi: 10.1136/bmj.f402.

12 Jones C, Hacker D, Cormac I, Meaden A, Irving CB. Cognitive behaviour therapy versus other psychosocial treatments for schizophrenia. Cochrane Database Syst Rev 2012; 4: CD008712.

13 Lynch D, Laws KR, McKenna PJ. Cognitive behavioural therapy for major psychiatric disorder: does it really work? A meta-analytical review of well-controlled trials. Psychol Med 2010; 40: 9-24.

14 Kingdon D. Over-simplification and exclusion of non-conforming studies can demonstrate absence of effect: a lynching party? Psychol Med 2010; 40: $25-7$.

15 Tarrier $\mathrm{N}$, Lewis $\mathrm{S}$, Haddock $\mathrm{G}$, Bentall $\mathrm{R}$, Drake $\mathrm{R}$, Kinderman $\mathrm{P}$, et al. Cognitive-behavioural therapy in first-episode and early schizophrenia: 18-month follow-up of a randomised controlled trial. Br J Psychiatry 2004; 184: 231-9.

16 Barrowclough C, Haddock G, Wykes T, Beardmore R, Conrod P, Craig T, et al. Integrated motivational interviewing and cognitive behavioural therapy for people with psychosis and comorbid substance misuse: randomised controlled trial. BMJ 2010; 341: c6325.

17 Haddock G, Barrowclough C, Tarrier N, Moring J, O'Brien R, Schofield N, et al. Cognitive-behavioural therapy and motivational intervention for schizophrenia and substance misuse: 18-month outcomes of a randomised controlled trial. Br J Psychiatry 2003; 183: 418-26.

18 National Institute for Health Research. NIHR Clinical Research Network Portfolio. NIHR, 2013.

19 Improving Access to Psychological Therapies. Severe mental illness. National Health Service (http://www.iapt.nhs.uk/smi-/, accessed 30 Apr 2013).

20 Improving Access to Psychological Therapies. Competencies and National Occupational Standards (Archived). National Health Service (http:// www.iapt.nhs.uk/about-iapt/website-archive/competencies-and-nationaloccupational-standards/?keywords = competencies, accessed 30 Apr 2013).

21 Fenton WS, McGlashan TH. We can talk: individual psychotherapy for schizophrenia. Am J Psychiatry 1997; 154: 1493-5. 